\title{
Review
}

\section{Bile Acids as Key Modulators of the Brain-Gut-Microbiota Axis in Alzheimer's Disease}

\author{
Agata Mulak* \\ Department of Gastroenterology and Hepatology, Wroclaw Medical University, Wroclaw, Poland
}

Accepted 24 August 2021

Pre-press 21 September 2021

\begin{abstract}
Recently, the concept of the brain-gut-microbiota (BGM) axis disturbances in the pathogenesis of Alzheimer's disease $(\mathrm{AD})$ has been receiving growing attention. At the same time, accumulating data revealing complex interplay between bile acids (BAs), gut microbiota, and host metabolism have shed new light on a potential impact of BAs on the BGM axis. The crosstalk between BAs and gut microbiota is based on reciprocal interactions since microbiota determines BA metabolism, while BAs affect gut microbiota composition. Secondary BAs as microbe-derived neuroactive molecules may affect each of three main routes through which interactions within the BGM axis occur including neural, immune, and neuroendocrine pathways. BAs participate in the regulation of multiple gut-derived molecule release since their receptors are expressed on various cells. The presence of BAs and their receptors in the brain implies a direct effect of BAs on the regulation of neurological functions. Experimental and clinical data confirm that disturbances in BA signaling are present in the course of AD. Disturbed ratio of primary to secondary BAs as well as alterations in BA concertation in serum and brain samples have been reported. An age-related shift in the gut microbiota composition associated with its decreased diversity and stability observed in AD patients may significantly affect BA metabolism and signaling. Given recent evidence on BA neuroprotective and anti-inflammatory effects, new therapeutic targets have been explored including gut microbiota modulation by probiotics and dietary interventions, ursodeoxycholic acid supplementation, and use of BA receptor agonists.
\end{abstract}

Keywords: Alzheimer's disease, bile acids, brain-gut-microbiota axis

\section{INTRODUCTION}

Recently, the concept of the brain-gut-microbiota (BGM) axis disturbances in the pathogenesis of Alzheimer's disease (AD) has been receiving growing attention $[1,2]$. Accumulating data indicate that amyloid- $\beta$ deposits constituting the characteristic feature of $\mathrm{AD}$ may occur at different levels of the axis including both the central and enteric nervous systems [2]. Importantly, gut microbiota is also the

\footnotetext{
*Correspondence to: Agata Mulak, MD, PhD, Department of Gastroenterology and Hepatology, Wroclaw Medical University, Borowska 213, 50-556 Wroclaw, Poland. Tel.: + 487173321 20; Fax: +48 7173321 29; E-mail: agata.mulak@wp.pl.
}

source of significant amount of amyloids [3]. Moreover, numerous alterations in the gut microbiota composition and function in AD patients have been reported [1-6]. The mechanisms involved in regulation of the BGM axis through which gut microbes can communicate to the brain include neural, immune, and neuroendocrine pathways [7, 8]. Additionally, microbial metabolites such as serotonin, dopamine, short-chain fatty acids, as well as secondary bile acids (BAs) may serve as direct neurotransmitters or neuromodulators $[8,9]$.

Over recent years there has been also growing understanding of the complex role of BAs in regulating host physiology and host-microbiota interactions 
[10-15]. In the past, BAs as naturally acting detergents were considered to play a cardinal role in the digestion, micelle formation, and absorption of fat and fat-soluble vitamins. Currently, they are recognized as important signaling molecules actively participating in the regulation of numerous metabolic processes and significantly affecting gastrointestinal motor, sensory and secretory functions, as well as intestinal barrier permeability and regulation of inflammatory response [16]. Given close interactions between BAs and gut microbiota, they emerge as potential modulators of the BGM axis that may have direct impact on neurodegeneration. In fact, numerous experimental and clinical studies confirm the BA involvement in the pathogenesis of $\mathrm{AD}$ [17-23]. This review is aimed at highlighting most recent progress in the field with respect to the BA impact on neural, immune, and neuroendocrine interactions within the BGM axis.

\section{BILE ACID SYNTHESIS, METABOLISM, AND ENTEROHEPATIC CIRCULATION}

While cholesterol metabolism is thought to play a pivotal role in the pathogenesis of $\mathrm{AD}, \mathrm{BAs}$ are the products of cholesterol clearance [24]. Importantly, many cholesterol metabolism-related genes (e.g., $A B C A 7, A B C G 1$, SORLI, BINI, CLU, and PICALM) are among the main AD susceptibility loci identified by genome-wide association studies $[25,26]$. Three different pathways of cholesterol clearance may be distinguished (reviewed in detail in [24]). The classic pathway, which is the main pathway of BA synthesis in the liver, begins with the conversion of cholesterol to $7 \alpha$-hydroxycholesterol by CYP7A1, which is subsequently hydroxylated by sterol $12 \alpha$-hydroxylase (CYP8B1) or sterol 27-hydroxylase (CYP27A1) to form the primary BAs: cholic acid (CA) and chenodeoxycholic acids (CDCA), respectively [27, 28]. The alternative BA synthesis pathway is mediated by CYP27A1, which unlike CYP7A1, is expressed in the mitochondria of most cells [28]. The second (acidic) pathway is responsible for about $5-10 \%$ of BA synthesis in humans, and about $25 \%$ in rodents [28]. The alternative pathway produces regulatory oxysterols [16]. The third pathway, called the neural one, is responsible for the majority of cholesterol turnover in the central nervous system (CNS) [29]. The brain clears excess cholesterol via CYP46A1 that catalyzes the conversion of cholesterol to 24Shydroxycholesterol, which being more polar than cholesterol can more easily pass the blood-brain barrier (BBB) to exit the brain and pass into the bloodstream [28]. It has been shown that in $A D$ patients, there is significantly decreased expression of cholesterol-24 hydroxylase in neurons [30].

Primary BAs (CA and CDCA) after conjugation in the liver with glycine or taurine are secreted into the bile and transported to the gut lumen when they are metabolized by bacteria. Gut microbiota initiates bile acid metabolism via a critical first step catalyzed by bile salt hydrolases (BSHs) [31]. These enzymes hydrolyze and deconjugate glycine or taurine from the sterol core of the primary BAs. Deconjugated BAs can subsequently undergo a variety of microbiotaencoded transformations (i.e., $7 \alpha$-dehydroxylation, dehydrogenation, and epimerization) that generate secondary BAs, which have widespread effects on the host and resident microbiota [31-33]. CA is converter to deoxycholic acid (DCA), while CDCA is converted to lithocholic acid (LCA) and ursodeoxycholic acids (UDCA) [31, 33].

In the terminal ileum about $95 \%$ of BAs are reabsorbed primarily through active transport by the apical sodium-dependent BA transporter (ASBT) [34]. Subsequently, they are released into the portal vein for return to the liver where they are conjugated to produce their glycine and taurine forms [35]. BAs, which are not reabsorbed in the ileum, enter the colon, and serve as substrates for microbial metabolism and undergo biotransformation to secondary BAs [36]. BAs regulate their own synthesis and transport via the nuclear farnesoid receptor (FXR). After binding to the ileal FXR, BAs induce expression of fibroblast growth factor FGF19 (FGF15 in mice), which travels via the portal bloodstream and binds to hepatocyte receptors repressing BA synthesis by inhibiting the rate-limiting enzyme CYP7A1 via negative feedback [37].

\section{BILE ACID SIGNALING}

A wide variety of BA characteristics is associated with their lipophilicity or hydrophilicity, but also with their ability to bind numerous receptors as well as activate ion channels [38]. While unconjugated BAs may be able to easily cross the plasma membrane, conjugated BAs might cross the plasma membrane using transporters. Nuclear receptors activated by $\mathrm{BAs}$ are the $\mathrm{FXR}$, pregnane $\mathrm{X}$ receptor (PXR), vitamin D receptor (VDR), liver $\mathrm{X}$ receptor (LXR), and glucocorticoid receptor (GR). Whereas 
G protein-coupled receptors (GPCR) on cell surface activated by BAs include Takeda G-protein receptor 5 (TGR5), sphingosine-1-phosphate receptor 2 (S1PR2), muscarinic receptors (M2 and M3), and formyl peptide receptor (FPR). Moreover, BAs are able to activate ion channels such as epithelial $\mathrm{Na}+$ channel $(\mathrm{ENaC})$, and large-conductance $\mathrm{Ca} 2+-$ and voltage-activated $\mathrm{K}+(\mathrm{BK})$ channels. Noteworthy, all these nuclear and membrane receptors as well as bile acid-sensitive ion channels (BASIC) are expressed in the brain [38].

BAs vary in their ability to activate nuclear receptors and GPCRs. FXR is activated most potently by the primary BA - CDCA, while TGR5 receptor is mainly activated by secondary BAs (LCA and DCA) [12]. Additionally, UDCA (secondary BA in humans) and murine primary BAs (T $\alpha \mathrm{MCA}$ and T $\beta M C A$ ) act as FXR antagonists. The ability to activate two major $\mathrm{BA}$ receptors occurs in the following order - for FXR: CDCA $>$ LCA $=$ DCA $>$ CA and for TGR5: LCA $>$ DCA $>$ CDCA $>$ CA [16, 39]. FXR is involved in BA synthesis, transport, and enterohepatic circulation as well as multiple glucose and lipid metabolic processes [40]. FXR is also a suppressor of inflammation in the liver and intestines and enhances epithelial barrier properties [41]. TGR5 being expressed on neuroendocrine cells induces glucagon-like peptide (GLP-1) release and plays an important role in glucose homeostasis [40, 42]. Moreover, TGR5 is also expressed in brown adipose tissue, muscles, and immune cells [43]. BA signaling through membrane-bound or nuclear receptors as well as neuromodulatory effects of BAs are accurately summarized in a graphic form in the review by McMillin and DeMorrow [27].

\section{INTESTINAL CROSSTALK BETWEEN BILE ACIDS AND GUT MICROBIOTA}

The crosstalk between BAs and gut microbiota is based on reciprocal interactions since microbiota determines BA metabolism, while BAs affect gut microbiota composition [12, 44, 45]. Gut microbes directly involved in BA biotransformation control the composition of BA pool, which in turn has a profound impact on the size of BA pool [11]. Comparing germ-free rodents to rodents with typical microbiota significant differences in the BA pool size have been confirmed [46]. Gut microbiota is also able to modulate BA synthesis impacting the enzyme reactions. For example, antibiotic treatment associated with microbiota depletion inhibits the expression of CYP7A1 [47]. The expression of CYP7A1 and CYP27A1 was also found to be reduced in germ-free mice compared to normal mice [48]. Changes in the BA pool composition associated with altered ratio of primary to secondary BAs may directly affect their signaling due to different affinities to their various receptors $[16,27,39]$.

On the other hand, BAs participate in the regulation of the gut microbiota composition by direct antimicrobial effects and indirect effects through FXR-induced antimicrobial peptide synthesis in the small intestine [49, 50]. In general, a decreased BA level in the gut lumen favors gram-negative bacteria containing lipopolysaccharides (LPS) in their outer membranes, whereas an increase in BA concentration appears to favor gram-positive bacteria such as Firmicutes that are able to turn primary BAs via $7 \alpha-$ hydroxylation to more toxic secondary BAs [11]. In a mouse model, biliary duct ligation resulted in overgrowth of aerobic and anaerobic bacteria in the ileum and cecum, but that overgrowth could be blocked by the FXR agonist [50]. Another clinically relevant example of BA impact on the gut microbiota ecosystem is infection with Clostridioides difficile. It has been shown that in a healthy intestinal environment microbiota-derived secondary BAs inhibit the growth of this pathogen. However, antibiotic-induced dysbiosis may result in a rapid shift in the BA pool leading to decreased secondary BA level that promotes the growth of $C$. difficile [48].

Clostridia are among a narrow group of commensal bacteria able to perform $7 \alpha$-dehydroxylation constituting a crucial reaction in secondary BA origination. Noteworthy, these spore-forming bacteria have also important impact on tryptophan metabolism in the gastrointestinal tract [51]. Golubeva et al. [52] have suggested some association between microbiota-related alterations in tryptophan metabolism and inadequate bacterial conversion of BAs that are both likely to contribute to intestinal dysmotility and impaired gut barrier function in a mouse model of autism.

Another interesting aspect of the connection between human and microbiota BA metabolism is related to probiotic BSH-containing strains like Lactobacillus and Bifidobacterium that not only participate in deconjugation of BAs but may also accumulate primary and secondary BAs in their cytoplasm either spontaneously or following intracellular BA deconjugation $[53,54]$. Accumulation of primary BAs in the cytoplasm of probiotic bacteria results 
in their reduced conversion to secondary BAs in the colon which may have some implications in chronic inflammation [53, 55].

\section{BILE ACIDS IN THE BRAIN}

The presence of twenty BAs and their receptors has been demonstrated in the brain $[38,56]$. Among them are unconjugated BAs (CA, CDC, DCA, and UDCA) and conjugated BAs (GDCA, TCA, TDCA, and TUDCA) which are related to brain physiology and pathophysiology [57]. Mano et al. [56] found that CDCA composes about $95 \%$ of total BA composition with CA and DCA being about 2-3\% in the rat brain. It has been also suggested that since BA level in the brain under normal conditions is approximately 10 -fold higher than circulating level, they may be actually synthesized locally [56]. It is consistent with the observation that BAs may serve as potent neuroactive steroids [58]. In fact, CDCA was found to be about 10 times more abundant than the prototypical neurosteroid pregnenolone [56]. However, BAs can be also transported into the brain from the peripheral circulation. While conjugated BAs require transporters to cross the $\mathrm{BBB}$, unconjugated and lipophilic BAs can cross the BBB by passive diffusion $[38,59]$. In addition, BAs in the bloodstream may affect the BBB permeability as it has been shown that phosphorylation of occludin-one of the tight junction proteins-may be increased by CDCA and DCA via ras-related $\mathrm{C} 3$ botulinum toxin substrate 1 (RAC1) [60]. On the other hand, UDCA and its glycine-conjugated form (GUDCA) exert a protective effect on brain endothelial cells by reducing apoptosis [61, 62].

Noteworthy, both amino acids, glycine and taurine, conjugated with BAs in the liver have neurotransmitter properties [63, 64]. Glycine is an inhibitory neurotransmitter in the CNS serving as a co-agonist along with glutamate for $\mathrm{N}$-methyl-D-aspartate (NMDA) receptors [63]. Taurine demonstrates functions of a neurotransmitter, neuromodulator, and neuroprotectant, and acts as a trophic factor in the CNS development. The neurotransmitter properties of taurine are illustrated by its ability to elicit neuronal hyperpolarization [64].

The role of BAs as neurosteroids is related to their affinity to receptors for several neurotransmitters $[38,58]$. TCA, GDCA, and TDCA activate muscarinic acetylcholine receptors $\left(\mathrm{M}_{2}\right.$ and $\left.\mathrm{M}_{3}\right)$ that are known to play an important role in cognitive function, memory, and learning [65]. Moreover, CDCA, DCA, and CA block both $\gamma$-aminobutyric acid type A $\left(\mathrm{GABA}_{\mathrm{A}}\right)$ receptors and NMDA receptors [66]. The NMDA receptor activation is also important for learning and memory [67], while $\mathrm{GABA}_{\mathrm{A}}$ activation leads to the inhibition of neurotransmission [68]. All these observations imply an important role of BAs in the regulation of neurological functions. Additionally, there are accumulating data supporting neuroprotective effect of some BAs such as TUDCA [38]. Their neuroprotective action may be associated with inhibition of amyloid- $\beta$ accumulation, mitochondrial damage, and apoptosis. It has been also suggested that TUDCA may induce neurogenesis in adults, but the mechanism of that action remains to be elucidated [38].

\section{INTERACTIONS BETWEEN BILE ACIDS AND THE BRAIN-GUT-MICROBIOTA AXIS}

Disturbances along the BGM axis may significantly contribute to the pathogenesis of $\mathrm{AD}[1,4$, 5]. Alterations in the gut microbiota composition induce increased permeability of the gut barrier and immune activation leading to systemic inflammation, which, in turn, may impair the BBB and promote neuroinflammation, neural injury, and ultimately neurodegeneration associated with the formation of amyloid- $\beta$ plaques and neurofibrillary tangles [1, 69-71]. Bacterial amyloids through molecular mimicry may elicit cross-seeding of misfolding and cause priming of the immune system, consequently enhancing immune response to endogenous production of neuronal amyloid in the brain [72]. Recognition of bacterial amyloid by the human TLR2 receptor (toll-like receptor 2) results in the release of pro-inflammatory cytokines such as Il- $1 \beta$ and Il6 produced by activated bone marrow macrophages as well as Il-11 and Il-17A produced by activated Tlymphocytes [73]. These cytokines are able to cross the BBB and induce the production of reactive oxygen species, activation of the TLR2/1 and NF- $\kappa \mathrm{B}$ signaling pathways, which are directly related to neuroinflammation and neurodegeneration $[74,75]$. Also bacterial LPS can bind with microglial cell receptors (TLR2, TLR4, and/or CD14) [76, 77]. In the brain of animals exposed to curli-producing bacteria enhanced microgliosis and astrogliosis together with increased expression of TLR2, Il-6, and TNF were found [31]. In addition, microglia activation further impairs phagocytosis leading to the accumulation of $\mathrm{A} \beta_{42}[78,79]$. 


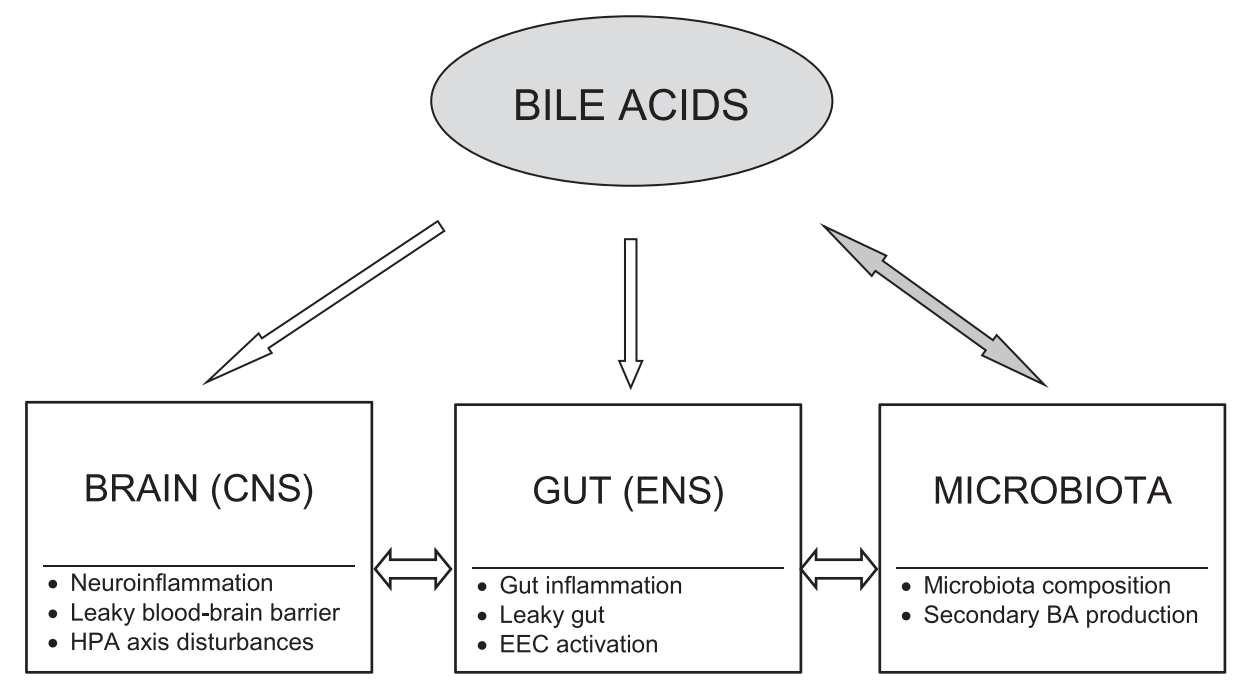

Fig. 1. Bile acid modulatory effects on the brain-gut-microbiota axis in Alzheimer's disease. Bile acids (BAs) may act as modulators of each level of the brain-gut-microbiota axis. There are bidirectional interactions between gut microbiota and BAs. The BA pool composition depends on gut microbiota producing secondary BAs, whereas BAs significantly influence microbiota composition. The primary to secondary BA ratio determines their signaling due to diversified binding affinities of BAs to various receptors. BAs may modify activation of both peripheral and central neural and immune cells as well as affect gut barrier and blood-brain barrier permeability. Moreover, BAs through their receptors exert neuroendocrine effects via enteroendocrine cells (EEC) and the hypothalamic-pituitary-adrenal (HPA) axis. CNS, central nervous system; ENS, enteric nervous system.

Recently, BAs possessing neuroactive properties have been emerging as a direct communication channel between the gut microbiome and the brain, since gut microbiota is directly involved in BA synthesis and metabolism affecting their pool composition and properties [80]. That, in turn, may affect BAs ability to bind and signal through their receptors.

The contribution of gut microbiota to the pathogenesis of $\mathrm{AD}$ is well depicted in animal models as well as clinical studies (reviewed in detail in [1]) [1, 5, 6, 70, 81]. Regarding interactions between BAs and gut microbiota, an important observation in AD patients concerns a decrease in Clostridium and Bifidobacterium [81]. Both genera have BSHs which allow BAs to become deconjugated and less toxic to the microbiota. Since BSHs are the only enzymes responsible for the pivotal deconjugation reaction, their activity serves as a gatekeeper to subsequent BA transformations [82]. BA deconjugation enables also subsequent metabolism of BAs via $7 \alpha$-dehydroxylation (Clostridium spp.) to secondary BAs which act as ligands for FXR [21]. The BA pool, influenced by microbial BSH activity, shapes in turn the microbiome composition and function [83]. The significant association between increased gut microbiota-derived secondary BAs both conjugated and unconjugated and changes in AD markers such as amyloid and tau proteins have been recently reported in AD patients by Nho et al. [19]. In that study serum-based BA metabolites were investigated and several BA ratios that reflect BA conversion by gut microbiota were assessed. Among numerous reported alterations in BA profiles, higher GDCA:CA levels were associated with greater global cortical amyloid deposition, while two conjugated secondary BA (GLCA and TLCA) were correlated with higher p-tau concertation in the cerebrospinal fluid (CSF) [19]. This observation supports the role of the gut microbiota transformation of BAs as a potential contributing factor in the pathogenesis and/or progression of $\mathrm{AD}$.

Moreover, a growing body of evidence indicates that BAs may serve as important modulators of each of three main routes through which interactions within the BGM axis occur including neural, immune, and neuroendocrine pathways that will be discussed below (Fig. 1). A wide spectrum of the BA effects may be exerted via their receptors found throughout the body. Among BA target cells are neurons, immune cells, and enteroendocrine cells [21].

\section{Neural pathways}

BA signaling via neural pathways may occur directly (via BA receptors present in the brain and enteric nervous system) or indirectly (via the FXR- 
FGF15/19 axis). The most studied BA receptors are found in the brain [84]. The function of FXR and TGR5 in the brain is still unclear, but it has been reported that FXR knockout mice showed disturbed neurotransmitter system and altered neurobehavior [85]. The results from studies with FXR knockout mice confirmed changes in serotoninergic as well as glutamatergic, GABAergic, norepinephrinergic neurotransmission in either the hippocampus or cerebellum [85]. Additionally, TGR5 being expressed on neurons, glial and microglial cells can be activated by numerous neurosteroids [86, 87]. In neurodegenerative processes such as $\mathrm{AD}, \mathrm{BA}$ receptors may significantly affect decline in cognitive function by affinity to muscarinic receptors as well as $\mathrm{GABA}_{\mathrm{A}}$ and NMDA receptors [66].

Among other BA receptors expressed in the brain, special attention in the context of AD is focused on pregnane $\mathrm{X}$ receptor (PXR), vitamin $\mathrm{D}$ receptor (VDR), and glucocorticoid receptor (GR) [38]. PXR as xenobiotic nuclear receptor activating cytochrome P450 can dispose toxins, for example at the BBB [88]. Vitamin D in the brain can act as neurosteroid and its beneficial effect in AD has been confirmed [89, 90]. The GR activation in the hypothalamus by BAs may suppress the hypothalamic-pituitary-adrenal (HPA) axis, which is the key arm of neuroendocrine interactions along the BGM axis [91]. Interestingly, UDCA can bind to and translocate GR [91].

Moreover, TGR5 receptors have been also identified in the enteric nervous system where their activation result in increased colonic motility, which may lead to BA-induced diarrhea [92]. Noteworthy, BA effects on the gastrointestinal tract may show regional differences between various segments of the tract, since for example activation of TGR5 on gastric smooth muscle results in delayed gastric emptying [92].

The indirect neural signaling pathway of BAs to the CNS involves FGF15/19. FGF19 can cross the BBB and bind to FGFRs that are also expressed in the brain, specifically in the hypothalamus, medial habenular nucleus and dorsal vagal complex [93]. FGF19 binds to FGFR4 but a more solid bond is created when $\beta$-Klotho, the FGF19 cofactor, is bound to FGF19-FGFR4 complex [61, 94].

\section{Immune pathways}

Although amyloid- $\beta$ deposition and tau pathology have been considered as the main features of AD, accumulating data show that disturbances in immune responses resulting in neuroinflammation considerably contribute to AD pathogenesis and may be even a trigger of the pathology [95-97]. The effect of BA action is determined by various factors such as concentration of BAs, their physicochemical properties, interactions with the gut microbiota and target cells [98]. Activation of BA receptors in immune cells results in several regulatory functions that are mainly inhibitory in nature [99]. Recent findings have been pointing at a crucial role of FXR in the modulation of inflammatory response and intestinal barrier integrity $[41,100]$. The results of both in vivo and in vitro studies have demonstrated that on the one hand the activation of FXR exerts antiinflammatory effect by reducing the production of pro-inflammatory cytokines such as TNF- $\alpha$, IFN- $\gamma$, interleukin-1 $\beta$ (IL-1 $\beta$ ), IL-2, and IL-6 [101]. On the other hand, inflammation reduces FXR expression [102]. It has been suggested that the reduced FXR transcriptional activity upon TNF- $\alpha / \mathrm{IL}-1 \beta$ stimulation is mediated by NF- $\kappa \mathrm{B}$ [41]. In fact, FXR and TGR5 knockout mice develop spontaneous intestinal inflammation [103, 104]. While in a mouse model of ulcerative colitis it has been demonstrated that experimental colitis may disturb BA synthesis by the negative feedback signaling within the FXR-FGF19 axis [105].

Additionally, both nuclear and membrane BA receptors are highly represented in immune cells such as intestinal and liver macrophages, dendritic cells, and natural killer T cells [99]. Activation of these receptors shifts the macrophage phenotype toward anti-inflammatory one (M2) with an upregulation of Il-10 and a downregulation of the pro-inflammatory cytokines including Il-6 and IFN- $\gamma$. In turn, Il-10 increases the production of Treg cells reducing the recruitment of monocytes from blood to the colon. The TGR5 signaling involves cAMP-protein kinase A (PKA)-mediated inhibition of NF- $\kappa \mathrm{B}$, and FXR signaling leads to repression of NF- $\kappa$ B-responsive elements. BA stimulation of both pathways blunt NF$\kappa \mathrm{B}$-dependent gene expression. Regarding action on dendritic cells, BAs downregulate the production of TNF- $\alpha$ and IL-12 [99].

Another important aspect of the BGM interactions and immune response concerns the integrity of intestinal and blood-brain barriers that may also be affected by BAs [106]. As mentioned above, BAs increase phosphorylation of occludin that may result in disruption of these barriers [60]. Additionally, TGR5 activated by BAs can activate the cJun $\mathrm{NH}_{2}$-terminal kinase (JNK) pathway lead- 
ing to degradation of tight junction proteins [107, 108]. Intestinal barrier integrity is also regulated by an interplay between gut symbionts and PXR through a pathway which involves luminal sensing and signaling by TLR4 [109]. Direct interactions between gut microbiota, gut immune system activation, and intestinal permeability constitute a critically important element of the BGM axis [1]. In fact, increased biomarkers of gut permeability and inflammation in AD has been recently reported [110]. An age-related shift in the gut microbiota composition associated with its decreased diversity and stability observed in AD patients may significantly affect BA metabolism and signaling [4, 5]. Additionally, dysbiosis-related intestinal inflammation and increased gut permeability are associated with an increase in proinflammatory cytokines and bacteriaderived products in the circulation resulting in systemic inflammation. Subsequently, due to concomitant BBB impairment, systemic inflammation may induce neuroinflammation observed in $\mathrm{AD}$ [1].

Interesting findings concern sex-dependent differences in aging-associated inflammation and dysregulation of systemic BA homeostasis [111-114]. Recently, sexual dimorphisms in human immune system aging have been reported pointing to higher innate and pro-inflammatory activity and lower adaptive activity in older men compared to older women [115]. The rate of BA synthesis and BA pool composition are also sexually dimorphic [116]. For example, in animal studies female mice have a larger total BA pool than males. Moreover, females excrete less fecal BA and catabolize less cholesterol via BA production than males [117]. Additionally, age-related hormonal changes are implicated in the differential production of BA in females [118]. Ma et al. [119] demonstrated that aging in mice has a greater impact on changing hepatic BA profiles in females, but gut BA profiles in males. Moreover, gut microbiota remodeling by co-housing with younger mice partially rescued the above changes in old mice [119]. Even more importantly, BAs and FXR as well as gut microbiota alterations are implicated in the sex-related differences in metabolic disorders, many of which constitute risk factors for AD [120]. Given the role of BA homeostasis disturbances in neurodegeneration, those sexdependent differences in BA profiles, especially in the elderly, could potentially explain female predominance in AD. Indeed, recently, Varma et al. [23] have suggested that cholesterol catabolism and BA synthesis may impact dementia progression through sexspecific effects on signaling pathways in the brain.

\section{Neuroendocrine pathways}

BAs as neurosteroids may exert a direct impact on the hypothalamus and the HPA axis. Suppression of the HPA axis has been shown to occur during cholestatic liver injury [69]. Furthermore, McMillin et al. [91] have demonstrated that in a model of cholestasis, serum BAs gain entry into the brain via a leaky BBB and that hypothalamic BA content is increased.

Currently, another neuroendocrine pathway in which BAs may be involved is emerging as BA receptors are expressed on enteroendocrine cells (EECs) forming the diffuse neuroendocrine system $[61,121$, 122]. These interactions may have direct clinical implications in AD. A particular group of EECs, Lcells, responsible for the production of glucagon-like peptide-1 (GLP-1), are predominantly located in the terminal ileum and the colon [123]. Secondary BAs are powerful stimulants of GLP-1 release through the activation of TGR5 receptors located at the basolateral membrane of L-cells [124]. Additionally, L-cells may release GLP-1 in response to other endocrine or neural signals, not involving BA-induced TGR5 activation [125]. Although BA receptors have not been found on the vagus nerve so far, vagal afferent fibers express GLP-1 receptors and are therefore responsive to local GLP-1 level [126]. The nodose ganglion projects to the nucleus of the solitary tract (NST in the hindbrain is connected with other brain regions including the hypothalamus) $[126,127]$. That points at the vagal-brainstem-hypothalamic pathway for the signal transmission of GLP-1 from the gastrointestinal tract to the CNS, which may be indirectly impacted by BAs [61].

Lately, GLP-1 and connections between its release and BA signaling are attracting attention as a possible link between metabolic and brain impairment $[128,129]$. GLP-1 not only plays a key regulatory role in glucose metabolism stimulating insulin secretion, inhibiting glucagon secretion, decreasing food intake, reducing appetite, and inducing weight reduction, but affects also neurological and cognitive functions [129]. Hyperinsulinemia and insulin resistance, which are known as pathophysiological features of type 2 diabetes and obesity, have also been demonstrated as risk factors for $\mathrm{AD}$ [130]. Importantly, GLP-1 receptor agonists are used in the treatment for diabetes and obesity [131]. Moreover, modulation of GLP-1 activity can influence amyloid$\beta$ aggregation in AD and GLP-1 receptor agonists reduce hippocampal neurodegeneration [132]. There 
is also growing evidence on neuroprotective effects of these agonists in animal models of neurodegenerative diseases, regardless of diabetes [128]. Physiological consequences of BA impact on the TGR5-dependent release of GLP-1 in patients with obesity and/or on high fat diet remain to be elucidated. Nonetheless, it has been recently highlighted that BA signaling mediated by gut microbiota may contribute to obesity susceptibility [40]. Therefore, modulation of BAs could be a promising therapeutic target in obesity and obesity-related diseases including AD.

It has been also shown that secondary BAs acting through TGR5 may activate intestinal stem cells and epithelial regeneration [133] as well as induce L-cell differentiation and serotonin signaling [134]. Of note, serotonin in $95 \%$ stored in the EECs, is a key mediator of the neuroendocrine pathway within the BGM axis $[135,136]$.

\section{BILE ACID DISTURBANCES IN EXPERIMENTAL AND CLINICAL SAMPLES OF ALZHEIMER'S DISEASE}

Substantial BA perturbations have been reported in AD. Pan et al. [17] performed metabolomic profiling of BAs in both experimental and clinical samples of AD. Quantification of BAs in brain tissue extract and plasma was performed using a BA kit enabling simultaneous evaluation of 22 BAs. Human brain samples in that study were obtained from postmortem confirmed AD cases, while mouse brain samples from APP/PS1 male mice. Pan et al. [17] found higher plasma CA level in APP/PS1 mice compared to wild type mice. Additionally, in the brains of APP/PS1 mice higher LCA and lower tauromuricholic (TMCA), $\beta$-muricholic, and $\Omega$-muricholic acids as well as lower TCA and TUDCA were demonstrated [17]. Intriguingly, CDCA was not detected in mouse brain [17], contrary to an earlier study performed in rats in which CDCA level in rat brain was approximately 30 times higher than those in the serum [56]. The beneficial or detrimental effects of BAs are related to their hydrophobicity or hydrophilicity. For example, hydrophobic BAs, like CDCA can damage biological membranes [137], while hydrophilic BAs, like UDCA and TUDCA, are able to inhibit apoptosis stabilizing mitochondrial membrane [138, 139].

In the above-mentioned study, Pan et al. [17] reported the following disturbances in BA profiles in clinical samples. In $\mathrm{AD}$ patients compared to age-matched control subjects lower plasma $\mathrm{CA}$ and lower brain TCA levels were found [17]. In contrast, the plasma level of LCA, a secondary BA known for its toxicity, was significantly higher in AD patients than in controls [140]. In another study the ratio of secondary to primary BAs (DCA/CA) in serum has been shown to be significantly higher in AD patients [18]. Higher level of microbiotaderived secondary conjugated BAs (GDCA, GLCA, and TLCA) were significantly associated with worse cognitive function [18]. Furthermore, in a followup study those changes were also correlated with alterations in CSF markers of the disease and with brain imaging changes [18]. Altogether, it suggests that the effects of gut-directed dysregulation of primary versus secondary BAs are not limited to the periphery but may also affect BA homeostasis and signaling in the human brain. Additionally, it supports the significance of the BGM axis interactions in the pathogenesis of $\mathrm{AD}$ in the context of BA disturbances [38]. Nevertheless, the casual relationship of these interactions needs to be further elucidated.

Interestingly, serum $\mathrm{BA}$ profile in $\mathrm{AD}$ has been shown to be associated with AD-related structural and functional neuroimaging as well as CSF biomarkers including amyloid- $\beta$, $t$-tau and $p$-tau [19]. For example, one conjugated primary BA (GCDCA) and two microbiota-derived conjugated secondary BAs (GLCA and TLCA) were associated with higher ttau and p-tau values, reduced glucose metabolism, and larger structural brain atrophy [19]. Very recently, Baloni et al. [20], based on the brain metabolic network analysis using $\mathrm{AD}$ patient-derived postmortem transcriptomics and metabolomics, have revealed differential usage of alternative BA pathway for cholesterol clearance in AD. Additionally, metabolomics analysis of postmortem brain samples identified higher ratio of GCDCA/CA and secondary BAs like DCA, LCA, TDCA, CDCA, and GDCA in $\mathrm{AD}$ compared to controls suggesting the association of those BAs with cognitive decline in $\mathrm{AD}$ [20]. The presence of secondary BAs in the brain metabolomics strongly points at the role of gut microbiome in AD.

Major limitations in BA research are differences in BA profiles and metabolism among species making it challenging to translate data from animal models to the clinic [45]. Noteworthy, not only significant differences in BA profiles have been reported between human and rodents, but also between mice and rats. These differences may result in discrepancies observed in experimental vs clinical studies, like for example alteration in CA plasma level that was lower in AD patients but higher in a mouse model of 
AD [17]. Another example concerns UDCA which is considered to be the primary BA in bears, beavers, and mice, but the secondary, microbiota-derived BA in humans [141]. Furthermore, in mice one of the main primary BAs is muricholic acids which is not present in humans and which can act as an antagonist of FXR/FGF15 axis [142]. In humans primary BAs act as potent FXR agonists [12]. Given these discrepancies caution in interpreting translational research is required.

Other important limitations in BA research in patients with $\mathrm{AD}$ are related to dietary factors, concomitant disorders such as obesity and diabetes, and medications including statins commonly used in the elderly that may directly or indirectly, via alterations in microbiota composition, affect BA synthesis and metabolisms [111]. On the one hand dietary patterns have impact on BA metabolism, while on the other hand food intake is partially regulated via BA-related changes in FXR and/or TGR5 signaling modulating the secretion of gastrointestinal hormones [143]. For example, in the study comparing BA profiles in vegans versus omnivores, a higher dietary fiber and lower fat intake was correlated with lower fecal BA concentrations [144]. Significant changes in dietary patterns leading to malnutrition are common in the elderly, and the lack of fiber and healthy fat intake can induce a state of systemic low-grade chronic inflammation [145]. Malnutrition itself is a risk factor for cognitive decline [146]. Eating and swallowing problems, which are present in about $80 \%$ of AD patients [147], along with the behavioral and psychological symptoms of dementia, can strongly affect nutritional status [148]. Moreover, an association between food intake and oral health problems common in the elderly may also contribute to neurodegeneration [149].

\section{THERAPEUTIC IMPLICATIONS AND PERSPECTIVES}

Given recent evidence on BA neuroprotective and anti-inflammatory effects their therapeutic potential has been intensively studied. In particular, better understanding of a critical role of BA-microbiota interactions in the regulation of metabolism and BGM axis has directed growing interest in microbiotabased approaches to modulate BA metabolism and associated conditions including neurodegeneration [15]. Numerous reports support the beneficial effect of probiotics by enhancing intestinal epithelial integrity, protecting against barrier disruption, reducing pro-inflammatory response, and inhibiting initiation or propagation of neuroinflammation and neurodegeneration [150, 151]. Additionally, probiotic administration may increase deconjugation of BAs and their fecal exertion in association with increased BSH activity in the gut and general modification of the microbiota composition [152, 153]. While supplementation with probiotics such as Lactobacillus and Bifidobacterium has been shown to improve significantly Mini-Mental State Examination scores in AD patients [154], administration of a BSH-positive Lactobacillus strain remarkably also reduces cholesterol levels in subjects with hypercholesterolemia [155].

Dysbiosis and dysregulated BA synthesis are implicated in Western diet-induced systemic inflammation, microglial activation, and reduced neuroplasticity [156]. Therefore, alternative approaches to manage diseases linked to BA dysmetabolism include dietary interventions aimed at modulating BA metabolism through balancing the microbiota [157]. Food-based therapies affect the gut microbiota composition or may have a direct influence on neuronal functioning in both the enteric and central nervous systems [158, 159]. The MIND diet, which is a hybrid of the Mediterranean and DASH (Dietary Approaches to Stop Hypertension) diets, was designed to emphasize nutrients that have been associated with dementia prevention and to eliminate products associated with increased risk of dementia [160]. Healthy diet is characterized by a high intake of fiber, probiotics, antioxidants, and omega3 polyunsaturated fatty acids, as well as low intake of animal-derived proteins, saturated fats, and refined sugar. Such a diet has been shown to inhibit inflammatory response, reduce insulin resistance, and decrease the risk of neurocognitive impairment and eventually the risk of $\mathrm{AD}[145,161]$. The use of prebiotics as food-compounds inducing the growth and/or activity of beneficial microorganisms is of particular interest. Among most studied prebiotics are nondigestible fibers such as inulin and fructooligosaccharides and dietary polyphenols [145]. A summary of the effects of probiotics and synbiotics (combination of pro- and prebiotics) in $\mathrm{AD}$ patients and animal models of $\mathrm{AD}$ is presented in an extensive review by Arora et al. [145]. Probiotic, prebiotic, and polyphenol-rich interventions have been reported to exert beneficial effects on fasting lipid profiles, with changes in the gut microbiota composition associated with lipid regulation [162]. 
Table 1

TUDCA effects in experimental models of Alzheimer's diseases

\begin{tabular}{|c|c|c|}
\hline Model/Subject & Effect & Ref. \\
\hline Mouse neuroblastoma cells & $\downarrow$ p53 and its downstream targets & {$[168]$} \\
\hline Rat cortical neurons & $\downarrow$ Translocation of pro-apoptotic Bax to the mitochondria & [173] \\
\hline \multirow[t]{3}{*}{ Rat neuronal-like PC12 cells } & $\downarrow$ E2F1-p53 apoptotic pathway & [174] \\
\hline & $\downarrow$ Caspases activation & {$[175]$} \\
\hline & $\downarrow$ JNK early activation & {$[176]$} \\
\hline $\begin{array}{l}\text { Rat neuronal-like PC12 cells and primary } \\
\text { cortical neuron }\end{array}$ & $\downarrow$ Anti-apoptotic $\Delta$ Np63 degradation & {$[177]$} \\
\hline Human cerebral endothelial cells & $\begin{array}{l}\downarrow \text { Apoptosis induced by the vasculotropic E22Q mutant of } \mathrm{A} \beta(\mathrm{A} \beta \mathrm{E} 22 \mathrm{Q}) \\
\downarrow \text { Cytochrome } c \text { release from mitochondria } \\
\downarrow \text { Bax translocation }\end{array}$ & {$[178]$} \\
\hline \multirow[t]{2}{*}{$\begin{array}{l}\text { APOE4 macrophages with ApoE4-induced ER } \\
\text { stress }\end{array}$} & $\uparrow$ Efferocytosis & [179] \\
\hline & $\begin{array}{l}\downarrow \text { Cell death } \\
\downarrow \text { LPS- and oxidized LDL-induced apoptosis }\end{array}$ & \\
\hline \multirow[t]{8}{*}{ APP/PS1 mice } & $\begin{array}{l}\downarrow \text { mEPSCs } \\
\uparrow \text { Number of dendritic spines } \\
\uparrow \text { Postsynaptic marker PSD-95 }\end{array}$ & {$[180]$} \\
\hline & $\downarrow$ Synaptic loss & [181] \\
\hline & $\downarrow A \beta$ plaque accumulation & {$[172,182]$} \\
\hline & $\uparrow$ Spatial, recognition, and contextual memory & \\
\hline & $\downarrow$ Activation of astrocytes and microglia & [172] \\
\hline & $\uparrow$ Immunoreactivity of MAP2 used as a marker of neuronal integrity & \\
\hline & $\downarrow A P O E$ gene expression & [172] \\
\hline & $\begin{array}{l}\downarrow \text { Amyloidogenic } A \beta P P \text { processing pathway } \\
\downarrow A \beta_{41} \text { and } A \beta_{42} \text { levels }\end{array}$ & {$[172,181]$} \\
\hline
\end{tabular}

ApoE, apolipoprotein E; AßPP, amyloid- $\beta$ protein precursor; Bax, Bcl-2-associated X protein; ER, endoplasmic reticulum; JNK, c-Jun N-terminal kinase; LPS, lipopolysaccharide; MAP2, microtubule-associated protein 2; mEPSCs, miniature excitatory postsynaptic currents; PS1, presenilin 1; PSD-95, postsynaptic density protein 95.

Additionally, the effect of fecal microbiota transplantation (FMT) is being investigated in many animal models exploring pathogenetic mechanisms of neurodegenerative disorders [163]. Recently, the first case report on rapid improvement in AD symptoms following FMT for $C$. difficile infection has been published [164]. Intriguingly, the main FMT action might be related to restoring secondary BA synthesis [165] that would confirm the role of BA in the modulation of $\mathrm{BGM}$ interactions in $\mathrm{AD}$.

Other options to modulate BA signaling include supplementation of neuroprotective BAs such as UDCA or TUDCA [166, 167]. Most central effects of TUDCA are dependent on the activation of TGR5, S1PR2, and $\alpha 5 \beta 1$-Integrin, which have already been identified in the brain [167]. Indeed, TUDCA has been shown to increase cell survival and inhibit neuronal apoptosis in a number of experimental models of neurodegenerative diseases such as AD, Huntington's disease, and Parkinson's disease [168, 169]. Furthermore, in animal model of acute neuroinflammation TUDCA exerts "triple" anti-inflammatory effect including reduction in glial cell activation, microglial cell migratory capacity, and expression of chemoattractants and vascular adhesion proteins
[170]. TUDCA also reduced the accumulation of amyloid- $\beta$ in the hippocampus and frontal cortex as well as rescued memory deficits in APP/PS1 transgenic mice [171, 172]. The TUDCA effects in experimental models of AD are summarized in Table 1. Although there is still no strong evidence on benefits in a clinical setting there are several ongoing registered trials with TUDCA and UDCA in AD, Parkinson's disease, Huntington's disease, amyotrophic lateral sclerosis, and progressive multiple sclerosis [167].

A promising new direction of BA research would be to target BA receptors and indirect pathways of BA signaling to the brain mediated by FXR-FGF19 and TGR5-GLP-1 axes [61, 183]. FXR agonists targeting the gut-liver axis may reduce gut inflammation and preserve the intestinal barrier [41] as well as improve metabolic disorders associated with increased risk for AD [184]. Furthermore, GLP-1 receptor agonists have been reported to exert therapeutic effect in diabetes, obesity, and cognitive decline [128].

BA co-metabolism of both host and gut microbiota, and the diversified binding affinities to BA receptors among primary, secondary, free, and conjugated BAs result in the immense complexity of BA signaling 
[47, 119]. The advent of new analytical tools and strategies such as metabolomics and metagenomics is expected to bring a rapid progress in gaining insight in these complex BA-gut microbiota-host interactions [47]. It should enable to elucidate not only therapeutic but also diagnostic potential of BAs, which may serve as disease biomarkers. Noteworthy, intensive efforts focusing on unraveling $\mathrm{BA}$ signaling in $\mathrm{AD}$ should take into account multiple confounding factors such as gut dysbiosis, diet, sex, age, concomitant disorders, and medications. Most importantly, the causal relationship between BA disturbances and the AD pathology needs to be verified.

\section{CONCLUSIONS}

Given a direct reciprocal crosstalk between gut microbiota and BAs, they are emerging as key signaling molecules within the BGM axis. Moreover, since bacteria-derived secondary BAs can not only affect the composition and function of gut microbiota but also can modulate host physiology, they have been recognized as interkingdom signaling molecules [11, 45]. BAs have even been called a communication channel tuning the BGM interactions [80]. The observed disturbances in BA homeostasis in experimental and clinical samples of AD support the association between BA and the AD pathology as well as the significance of the BGM axis [32]. It indicates some potential therapeutic targets including gut microbiota modification, UDCA supplementation or administration of BA receptor agonists. The application of multi-omics techniques in unraveling the molecular mechanisms that underly BA-gut microbiota-host interactions should help to provide the basis for interventional studies.

\section{DISCLOSURE STATEMENT}

The author's disclosure is available online (https:// www.j-alz.com/manuscript-disclosures/21-0608r1).

\section{REFERENCES}

[1] Kowalski K, Mulak A (2019) Brain-gut-microbiota axis in Alzheimer's disease. J Neurogastroenterol Motil 25, 48-60.

[2] Semar S, Klotz M, Letiembre M, Van Ginneken C, Braun A, Jost V, Bischof M, Lammers WJ, Liu Y, Fassbender K, Wyss-Coray T, Kirchhoff F, Schäfer KH (2013) Changes of the enteric nervous system in amyloid-beta protein precursor transgenic mice correlate with disease progression. J Alzheimers Dis 36, 7-20.
[3] Zhao Y, Dua P, Lukiw WJ (2015) Microbial sources of amyloid and relevance to amyloidogenesis and Alzheimer's disease (AD). J Alzheimers Dis Parkinsonism 5, 177.

[4] Quigley EMM (2017) Microbiota-brain-gut axis and neurodegenerative diseases. Curr Neurol Neurosci Rep 17, 94.

[5] Sochocka M, Donskow-Łysoniewska K, Diniz BS, Kurpas D, Brzozowska E, Leszek J (2019) The gut microbiome alterations and inflammation-driven pathogenesis of Alzheimer's disease-a critical review. Mol Neurobiol 56, 1841-1851.

[6] He Y, Li B, Sun D, Chen S (2020) Gut microbiota: Implications in Alzheimer's disease. J Clin Med 9, 2042.

[7] Dinan TG, Cryan JF (2017) Gut instincts: Microbiota as a key regulator of brain development, ageing and neurodegeneration. J Physiol 595, 489-503.

[8] Martin CR, Osadchiy V, Kalani A, Mayer EA (2018) The brain-gut-microbiome axis. Cell Mol Gastroenterol Hepatol 6, 133-148.

[9] Mayer EA, Tillisch K, Gupta A (2015) Gut/brain axis and the microbiota. J Clin Invest 125, 926-938.

[10] Grenham S, Clarke G, Cryan JF, Dinan TG (2011) Braingut-microbe communication in health and disease. Front Physiol 2, 94.

[11] Ridlon JM, Kang DJ, Hylemon PB, Bajaj JS (2014) Bile acids and the gut microbiome. Curr Opin Gastroenterol 30, 332-338.

[12] Wahlström A, Sayin SI, Marschall HU, Bäckhed F (2016) Intestinal crosstalk between bile acids and microbiota and its impact on host metabolism. Cell Metab 24, 41-50.

[13] Chàvez-Talavera $\mathrm{O}$, Tailleux $\mathrm{A}$, Lefebvre $\mathrm{P}$, Staels $\mathrm{B}$ (2017) Bile acid control of metabolism and inflammation in obesity, type 2 diabetes, dyslipidemia, and nonalcoholic fatty liver disease. Gastroenterology 152, 1679-1694.e3.

[14] Molinaro A, Wahlström A, Marschall HU (2018) Role of bile acids in metabolic control. Trends Endocrinol Metab 29, 31-41.

[15] Molinero N, Ruiz L, Sànchez B, Margolles A, Delgado S (2019) Intestinal bacteria interplay with bile and cholesterol metabolism: Implications on host physiology. Front Physiol 10, 185.

[16] Zhou H, Hylemon PB (2014) Bile acids are nutrient signaling hormones. Steroids 86, 62-68.

[17] Pan X, Elliott CT, McGuinness B, Passmore P, Kehoe PG, Hölscher C, McClean PL, Graham SF, Green BD (2017) Metabolomic profiling of bile acids in clinical and experimental samples of Alzheimer's disease. Metabolites $7,28$.

[18] MahmoudianDehkordi S, Arnold M, Nho K, Ahmad S, Jia W, Xie G, Louie G, Kueider-Paisley A, Moseley MA, Thompson JW, St John Williams L, Tenenbaum JD, Blach C, Baillie R, Han X, Bhattacharyya S, Toledo JB, Schafferer S, Klein S, Koal T, Risacher SL, Kling MA, Motsinger-Reif A, Rotroff DM, Jack J, Hankemeier T, Bennett DA, De Jager PL, Trojanowski JQ, Shaw LM, Weiner MW, Doraiswamy PM, van Duijn CM, Saykin AJ, Kastenmüller G, Kaddurah-Daouk R; Alzheimer's Disease Neuroimaging Initiative and the Alzheimer Disease Metabolomics Consortium (2019) Altered bile acid profile associates with cognitive impairment in Alzheimer's disease-An emerging role for gut microbiome. Alzheimers Dement 15, 76-92.

[19] Nho K, Kueider-Paisley A, MahmoudianDehkordi S, Arnold M, Risacher SL, Louie G, Blach C, Baillie R, Han 
X, Kastenmüller G, Jia W, Xie G, Ahmad S, Hankemeier T, van Duijn CM, Trojanowski JQ, Shaw LM, Weiner MW, Doraiswamy PM, Saykin AJ, Kaddurah-Daouk R; Alzheimer's Disease Neuroimaging Initiative and the Alzheimer Disease Metabolomics Consortium (2019) Altered bile acid profile in mild cognitive impairment and Alzheimer's disease: Relationship to neuroimaging and CSF biomarkers. Alzheimers Dement 15, 232-244.

[20] Baloni P, Funk CC, Yan J, Yurkovich JT, Kueider-Paisley A, Nho K, Heinken A, Jia W, Mahmoudiandehkordi S, Louie G, Saykin AJ, Arnold M, Kastenmüller G, Griffiths WJ, Thiele I; Alzheimer's Disease Metabolomics Consortium, Kaddurah-Daouk R, Price ND (2020) Metabolic network analysis reveals altered bile acid synthesis and metabolism in Alzheimer's disease. Cell Rep Med 1, 100138.

[21] Jia W, Rajani C, Kaddurah-Daouk R, Li H (2020) Expert insights: The potential role of the gut microbiome-bile acid-brain axis in the development and progression of Alzheimer's disease and hepatic encephalopathy. Med Res Rev 40, 1496-1507.

[22] Grant SM, DeMorrow S (2020) Bile acid signaling in neurodegenerative and neurological disorders. Int J Mol Sci 21, 5982.

[23] Varma VR, Wang Y, An Y, Varma S, Bilgel M, Doshi J, Legido-Quigley C, Delgado JC, Oommen AM, Roberts JA, Wong DF, Davatzikos C, Resnick SM, Troncoso JC, Pletnikova O, O'Brien R, Hak E, Baak BN, Pfeiffer R, Baloni P, Mohmoudiandehkordi S, Nho K, KaddurahDaouk R, Bennett DA, Gadalla SM, Thambisetty M (2021) Bile acid synthesis, modulation, and dementia: A metabolomic, transcriptomic, and pharmacoepidemiologic study. PLoS Med 18, e1003615.

[24] Di Paolo G, Kim TW (2011) Linking lipids to Alzheimer's disease: Cholesterol and beyond. Nature Rev Neurosci 12, 284-296.

[25] Sampson TR, Mazmanian SK (2015) Control of brain development, function, and behavior by the microbiome. Cell Host Microbe 17, 565-576.

[26] Beecham GW, Hamilton K, Naj AC, Martin ER, Huentelman M, Myers AJ, Corneveaux JJ, Hardy J, Vonsattel JP, Younkin SG, Bennett DA, De Jager PL, Larson EB, Crane PK, Kamboh MI, Kofler JK, Mash DC, Duque L, Gilbert JR, Gwirtsman H, Buxbaum JD, Kramer P, Dickson DW, Farrer LA, Frosch MP, Ghetti B, Haines JL, Hyman BT, Kukull WA, Mayeux RP, Pericak-Vance MA, Schneider JA, Trojanowski JQ, Reiman EM; Alzheimer's Disease Genetics Consortium (ADGC), Schellenberg GD, Montine TJ (2014) Genome-wide association meta-analysis of neuropathologic features of Alzheimer's disease and related dementias. PLoS Genet 10, e1004606.

[27] McMillin M, DeMorrow S (2016) Effects of bile acids on neurological function and disease. FASEB J 30, 36583668.

[28] Russell DW (2003) The enzymes, regulation, and genetics of bile acid synthesis. Annu Rev Biochem 72, 137-174.

[29] Lund EG, Guileyardo JM, Russell DW (1999) cDNA cloning of cholesterol 24-hydroxylase, a mediator of cholesterol homeostasis in the brain. Proc Natl Acad Sci U S A 96, 7238-7243.

[30] Garcia AN, Muniz MT, Souza e Silva HR, da Silva HA, Athayde-Junior L (2009) Cyp46 polymorphisms in Alzheimer's disease: A review. J Mol Neurosci 39, 342-345.
[31] Ridlon JM, Kang DJ, Hylemon PB (2006) Bile salt biotransformations by human intestinal bacteria. J Lipid Res 47, 241-259.

[32] Fiorucci S, Distrutti E (2015) Bile acid-activated receptors, intestinal microbiota, and the treatment of metabolic disorders. Trends Mol Med 21, 702-714.

[33] Zhan K, Zheng H, Li J, Wu H, Qin S, Luo L, Huang S (2020) Gut microbiota-bile acid crosstalk in diarrheairritable bowel syndrome. Biomed Res Int 2020, 3828249.

[34] Chiang JY (2013) Bile acid metabolism and signaling. Compr Physiol 3, 1191-1212.

[35] Chiang JYL, Ferrell JM (2018) Bile acid metabolism in liver pathobiology. Gene Expr 18, 71-87.

[36] Staley C, Weingarden AR, Khoruts A, Sadowsky MJ (2017) Interaction of gut microbiota with bile acid metabolism and its influence on disease states. Appl Microbiol Biotechnol 101, 47-64.

[37] Lee FY, Lee H, Hubbert ML, Edwards PA, Zhang Y (2006) FXR, a multipurpose nuclear receptor. Trends Biochem Sci 31, 572-580.

[38] Kiriyama Y, Nochi H (2019) The biosynthesis, signaling, and neurological functions of bile acids. Biomolecules $\mathbf{9}$, 232.

[39] Kawamata Y, Fujii R, Hosoya M, Harada M, Yoshida H, Miwa M, Fukusumi S, Habata Y, Itoh T, Shintani Y, Hinuma S, Fujisawa Y, Fujino M (2003) A G proteincoupled receptor responsive to bile acids. J Biol Chem 278, 9435-9440.

[40] Wei M, Huang F, Zhao L, Zhang Y, Yang W, Wang S, Li M, Han X, Ge K, Qu C, Rajani C, Xie G, Zheng X, Zhao A, Bian Z, Jia W (2020) A dysregulated bile acidgut microbiota axis contributes to obesity susceptibility. EBioMedicine 55, 102766.

[41] Gadaleta RM, van Erpecum KJ, Oldenburg B, Willemsen EC, Renooij W, Murzilli S, Klomp LW, Siersema PD, Schipper ME, Danese S, Penna G, Laverny G, Adorini L, Moschetta A, van Mil SW (2011) Farnesoid X receptor activation inhibits inflammation and preserves the intestinal barrier in inflammatory bowel disease. Gut 60, 463-472.

[42] Taylor SA, Green RM (2018) Bile acids, microbiota, and metabolism. Hepatology 68, 1229-1231.

[43] Watanabe M, Houten SM, Mataki C, Christoffolete MA, Kim BW, Sato H, Messaddeq N, Harney JW, Ezaki O, Kodama T, Schoonjans K, Bianco AC, Auwerx J (2006) Bile acids induce energy expenditure by promoting intracellular thyroid hormone activation. Nature 439, 484-489.

[44] Ramírez-Pèrez O, Cruz-Ramón V, Chinchilla-López P, Mèndez-Sànchez N (2017) The role of the gut microbiota in bile acid metabolism. Ann Hepatol 16(Suppl 1), S21-S26.

[45] Winston JA, Theriot CM (2020) Diversification of host bile acids by members of the gut microbiota. Gut Microbes 11, 158-171.

[46] Sayin SI, Wahlström A, Felin J, Jäntti S, Marschall HU, Bamberg K, Angelin B, Hyötyläinen T, Orešič M, Bäckhed F (2013) Gut microbiota regulates bile acid metabolism by reducing the levels of tauro-beta-muricholic acid, a naturally occurring FXR antagonist. Cell Metab 17, 225-235.

[47] Feng CC, Zhang AH, Miao JH, Sun H, Han Y, Yan GL, Wu FF, Wang IJ (2018) Recent advances in understadning cross-talk between bile acids and gut microbiota. Open $J$ Proeom Genom 3, 024-034.

[48] Qiu S, Zhang A, Zhang T, Sun H, Guan Y, Yan G, Wang X (2017) Dissect new mechanistic insights for 
geniposide efficacy on the hepatoprotection using multiomics approach. Oncotarget 8, 108760-108770.

[49] Islam KB, Fukiya S, Hagio M, Fujii N, Ishizuka S, Ooka T, Ogura Y, Hayashi T, Yokota A (2011) Bile acid is a host factor that regulates the composition of the cecal microbiota in rats. Gastroenterology 141, 1773-1781.

[50] Inagaki T, Moschetta A, Lee YK, Peng L, Zhao G, Downes M, Yu RT, Shelton JM, Richardson JA, Repa JJ, Mangelsdorf DJ, Kliewer SA (2006) Regulation of antibacterial defense in the small intestine by the nuclear bile acid receptor. Proc Natl Acad Sci U S A 103, 3920-3925.

[51] Yano JM, Yu K, Donaldson GP, Shastri GG, Ann P, Ma L, Nagler CR, Ismagilov RF, Mazmanian SK, Hsiao EY (2015) Indigenous bacteria from the gut microbiota regulate host serotonin biosynthesis. Cell 161, 264-276.

[52] Golubeva AV, Joyce SA, Moloney G, Burokas A, Sherwin E, Arboleya S, Flynn I, Khochanskiy D, Moya-Pèrez A, Peterson V, Rea K, Murphy K, Makarova O, Buravkov S, Hyland NP, Stanton C, Clarke G, Gahan CGM, Dinan TG, Cryan JF (2017) Microbiota-related changes in bile acid \& tryptophan metabolism are associated with gastrointestinal dysfunction in a mouse model of autism. EBioMedicine 24, 166-178.

[53] Sànchez B (2018) Bile acid-microbiota crosstalk in gastrointestinal inflammation and carcinogenesis: A role for bifidobacteria and lactobacilli? Nat Rev Gastroenterol Hepatol 15, 205.

[54] Kurdi P, van Veen HW, Tanaka H, Mierau I, Konings WN, Tannock GW, Tomita F, Yokota A (2000) Cholic acid is accumulated spontaneously, driven by membrane deltapH, in many lactobacilli. Bacteriol 182, 6525-6528.

[55] Jia W, Xie G, Jia W (2018) Bile acid-microbiota crosstalk in gastrointestinal inflammation and carcinogenesis. Nat Rev Gastroenterol Hepatol 15, 111-128.

[56] Mano N, Goto T, Uchida M, Nishimura K, Ando M, Kobayashi N, Goto J (2004) Presence of protein-bound unconjugated bile acids in the cytoplasmic fraction of rat brain. J Lipid Res 45, 295-300.

[57] Zheng X, Chen T, Zhao A, Wang X, Xie G, Huang F, Liu J, Zhao Q, Wang S, Wang C, Zhou M, Panee J, He Z, Jia W (2016) The brain metabolome of male rats across the lifespan. Sci Rep 6, 24125.

[58] Quinn M, DeMorrow S (2012) Bile in the brain? A role for bile acids in the central nervous system. $J$ Cell Sci Ther 3, 7 .

[59] Hanafi NI, Mohamed AS, Sheikh Abdul Kadir SH, Othman MHD (2018) Overview of bile acids signaling and perspective on the signal of ursodeoxycholic acid, the most hydrophilic bile acid, in the heart. Biomolecules 8, 159.

[60] Quinn M, McMillin M, Galindo C, Frampton G, Pae HY, DeMorrow S (2014) Bile acids permeabilize the blood brain barrier after bile duct ligation in rats via Rac1dependent mechanisms. Dig Liver Dis 46, 527-534.

[61] Mertens KL, Kalsbeek A, Soeters MR, Eggink HM (2017) Bile acid signaling pathways from the enterohepatic circulation to the central nervous system. Front Neurosci 11, 617.

[62] Palmela I, Correia L, Silva RF, Sasaki H, Kim KS, Brites D, Brito MA (2015) Hydrophilic bile acids protect human blood-brain barrier endothelial cells from disruption by unconjugated bilirubin: An in vitro study. Front Neurosci 9, 80 .

[63] Hernandes MS, Troncone LR (2009) Glycine as a neurotransmitter in the forebrain: A short review. J Neural Transm (Vienna) 116, 1551-1560.
[64] Wu JY, Prentice H (2010) Role of taurine in the central nervous system. J Biomed Sci 17(Suppl 1), S1.

[65] Abrams P, Andersson KE, Buccafusco JJ, Chapple C, de Groat WC, Fryer AD, Kay G, Laties A, Nathanson NM, Pasricha PJ, Wein AJ (2006) Muscarinic receptors: Their distribution and function in body systems, and the implications for treating overactive bladder. Br J Pharmacol 148, 565-578.

[66] Schubring SR, Fleischer W, Lin JS, Haas HL, Sergeeva OA (2012) The bile steroid chenodeoxycholate is a potent antagonist at NMDA and GABA(A) receptors. Neurosci Lett 506, 322-326.

[67] Kumar, A (2015) NMDA receptor function during senescence: Implication on cognitive performance. Front Neurosci 9, 473.

[68] Cicek SS (2018) Structure-dependent activity of natural GABA(A) receptor modulators. Molecules 23, 1512.

[69] La Rosa F, Clerici M, Ratto D, Occhinegro A, Licito A, Romeo M, Iorio CD, Rossi P (2018) The gut-brain axis in Alzheimer's disease and omega-3. A critical overview of clinical trials. Nutrients $\mathbf{1 0}, 1267$.

[70] Liu S, Gao J, Zhu M, Liu K, Zhang HL (2020) Gut microbiota and dysbiosis in Alzheimer's disease: Implications for pathogenesis and treatment. Mol Neurobiol 57, 50265043.

[71] Vogt NM, Kerby RL, Dill-McFarland KA, Harding SJ, Merluzzi AP, Johnson SC, Carlsson CM, Asthana S, Zetterberg H, Blennow K, Bendlin BB, Rey FE (2017) Gut microbiome alterations in Alzheimer's disease. $\mathrm{Sci}$ Rep 7, 13537.

[72] Friedland RP, Chapman MR (2017) The role of microbial amyloid in neurodegeneration. PLoS Pathog 13, e1006654.

[73] Askarova S, Umbayev B, Masoud AR, Kaiyrlykyzy A, Safarova Y, Tsoy A, Olzhayev F, Kushugulova A (2020) The links between the gut microbiome, aging, modern lifestyle and Alzheimer's disease. Front Cell Infect Microbiol 10, 104.

[74] Li CQ, Zheng Q, Wang Q, Zeng QP (2016) Biotic/abiotic stress-driven Alzheimer's disease. Front Cell Neurosci 10, 269.

[75] Megur A, Baltriukiene D, Bukelskiene V, Burokas A (2020) The microbiota-gut-brain axis and Alzheimer's disease: Neuroinflammation is to blame? Nutrients 13, 37.

[76] Lukiw WJ (2016) Bacteroides fragilis lipopolysaccharide and inflammatory signaling in Alzheimer's disease. Front Microbiol 7, 1544.

[77] Liu CY, Wang X, Liu C, Zhang HL (2019) Pharmacological targeting of microglial activation: New therapeutic approach. Front Cell Neurosci 13, 514.

[78] Cerovic M, Forloni G, Balducci C (2019) Neuroinflammation and the gut microbiota: Possible alternative therapeutic targets to counteract Alzheimer's disease? Front Aging Neurosci 11, 284

[79] Krabbe G, Halle A, Matyash V, Rinnenthal JL, Eom GD, Bernhardt U, Miller KR, Prokop S, Kettenmann H, Heppner FL (2013) Functional impairment of microglia coincides with Beta-amyloid deposition in mice with Alzheimer-like pathology. PLoS One 8, e60921.

[80] Monteiro-Cardoso VF, Corlianò M, Singaraja RR (2021) Bile acids: A communication channel in the gut-brain axis. Neuromolecular Med 23, 99-117.

[81] Zhuang ZQ, Shen LL, Li WW, Fu X, Zeng F, Gui L, Lü Y, Cai M, Zhu C, Tan YL, Zheng P, Li HY, Zhu J, Zhou $\mathrm{HD}, \mathrm{Bu}$ XL, Wang YJ (2018) Gut microbiota is altered 
in patients with Alzheimer's disease. J Alzheimers Dis 63, 1337-1346.

[82] Foley MH, O'Flaherty S, Barrangou R, Theriot CM (2019) Bile salt hydrolases: Gatekeepers of bile acid metabolism and host-microbiome crosstalk in the gastrointestinal tract. PLoS Pathog 15, e1007581.

[83] Nie YF, Hu J, Yan XH (2015) Cross-talk between bile acids and intestinal microbiota in host metabolism and health. $J$ Zhejiang Univ Sci B 16, 436-446.

[84] Huang C, Wang J, Hu W, Wang C, Lu X, Tong L, Wu F, Zhang W (2016) Identification of functional farnesoid X receptors in brain neurons. FEBS Lett 590, 32333242 .

[85] Huang F, Wang T, Lan Y, Yang L, Pan W, Zhu Y, Lv B, Wei Y, Shi H, Wu H, Zhang B, Wang J, Duan X, Hu Z, Wu $X$ (2015) Deletion of mouse FXR gene disturbs multiple neurotransmitter systems and alters neurobehavior. Front Behav Neurosci 9, 70.

[86] Keitel V, Görg B, Bidmon HJ, Zemtsova I, Spomer L, Zilles K, Häussinger D (2010) The bile acid receptor TGR5 (Gpbar-1) acts as a neurosteroid receptor in brain. Glia 58, 1794-1805.

[87] Yanguas-Casàs N, Barreda-Manso MA, Nieto-Sampedro M, Romero-Ramírez L (2017) TUDCA: An agonist of the bile acid receptor GPBAR1/TGR5 with anti-inflammatory effects in microglial cells. J Cell Physiol 232, 22312245.

[88] Litwa E, Rzemieniec J, Wnuk A, Lason W, Krzeptowski W, Kajta M (2016) RXR $\alpha$, PXR and CAR xenobiotic receptors mediate the apoptotic and neurotoxic actions of nonylphenol in mouse hippocampal cells. J Steroid Biochem Mol Biol 156, 43-52.

[89] Landel V, Annweiler C, Millet P, Morello M, Fèron F (2016) Vitamin D, cognition and Alzheimer's disease: The therapeutic benefit is in the D-tails. J Alzheimers Dis 53, 419-444.

[90] Morello M, Landel V, Lacassagne E, Baranger K, Annweiler C, Fèron F, Millet P (2018) Vitamin D improves neurogenesis and cognition in a mouse model of Alzheimer's disease. Mol Neurobiol 55, 6463-6479.

[91] McMillin M, Frampton G, Quinn M, Divan A, Grant S, Patel N, Newell-Rogers K, DeMorrow S (2015) Suppression of the HPA axis during cholestasis can be attributed to hypothalamic bile acid signaling. Mol Endocrinol 29, 1720-1730.

[92] Ticho AL, Malhotra P, Dudeja PK, Gill RK, Alrefai W (2019) Bile acid receptors and gastrointestinal functions. Liver Res 3, 31-39.

[93] Hsuchou H, Pan W, Kastin AJ (2013) Fibroblast growth factor 19 entry into brain. Fluids Barriers CNS 10, 32.

[94] Wu X, Ge H, Gupte J, Weiszmann J, Shimamoto G, Stevens J, Hawkins N, Lemon B, Shen W, Xu J, Veniant MM, Li YS, Lindberg R, Chen JL, Tian H, Li Y (2017) Co-receptor requirements for fibroblast growth factor-19 signaling. J Biol Chem 282, 29069-29072.

[95] Le Page A, Dupuis G, Frost EH, Larbi A, Pawelec G, Witkowski JM, Fulop T (2018) Role of the peripheral innate immune system in the development of Alzheimer's disease. Exp Gerontol 107, 59-66.

[96] Cai Z, Hussain MD, Yan LJ (2014) Microglia, neuroinflammation, and beta-amyloid protein in Alzheimer's disease. Int J Neurosci 124, 307-321.

[97] Minter MR, Taylor JM, Crack PJ (2016) The contribution of neuroinflammation to amyloid toxicity in Alzheimer's disease. J Neurochem 136, 457-474.
[98] Appleby RN, Walters JR (2014) The role of bile acids in functional GI disorders. Neurogastroenterol Motil 26, 1057-1069.

[99] Fiorucci S, Biagioli M, Zampella A, Distrutti E (2018) Bile acids activated receptors regulate innate immunity. Front Immunol 9, 1853.

[100] Hofmann AF (1999) The continuing importance of bile acids in liver and intestinal disease. Arch Intern Med 159, 2647-2658.

[101] Vavassori P, Mencarelli A, Renga B, Distrutti E, Fiorucci S (2009) The bile acid receptor FXR is a modulator of intestinal innate immunity. J Immunol 183, 6251-6261.

[102] Hofmann AF, Eckmann L (2006) How bile acids confer gut mucosal protection against bacteria. Proc Natl Acad Sci U S A 103, 4333-4334.

[103] Mencarelli A, Renga B, Migliorati M, Cipriani S, Distrutti E, Santucci L, Fiorucci S (2009) The bile acid sensor farnesoid $\mathrm{X}$ receptor is a modulator of liver immunity in a rodent model of acute hepatitis. J Immunol 183, 6657-6666.

[104] Cipriani S, Mencarelli A, Chini MG, Distrutti E, Renga B, Bifulco G, Baldelli F, Donini A, Fiorucci S (2011) The bile acid receptor GPBAR-1 (TGR5) modulates integrity of intestinal barrier and immune response to experimental colitis. PLoS One 6, e25637.

[105] Zhou X, Cao L, Jiang C, Xie Y, Cheng X, Krausz KW, Qi Y, Sun L, Shah YM, Gonzalez FJ, Wang G, Hao H (2014) PPARalpha-UGT axis activation represses intestinal FXRFGF15 feedback signalling and exacerbates experimental colitis. Nat Commun 5, 4573.

[106] Sarathy J, Detloff SJ, Ao M, Khan N, French S, Sirajuddin H, Nair T, Rao M (2017) The yin and yang of bile acid action on tight junctions in a model colonic epithelium. Physiol Rep 5, e13294.

[107] Gonzàlez-Mariscal L, Tapia R, Chamorro D (2008) Crosstalk of tight junction components with signaling pathways. Biochim Biophys Acta 1778, 729-756.

[108] Ferreira DM, Afonso MB, Rodrigues PM, Simão AL, Pereira DM, Borralho PM, Rodrigues CM, Castro RE (2014) c-Jun N-Terminal Kinase 1/c-Jun activation of the p53/MicroRNA 34a/Sirtuin 1 pathway contributes to apoptosis induced by deoxycholic acid in rat liver. $\mathrm{Mol}$ Cell Biol 34, 1100-1120.

[109] Venkatesh M, Mukherjee S, Wang H, Li H, Sun K, Benechet AP, Qiu Z, Maher L, Redinbo MR, Phillips RS, Fleet JC, Kortagere S, Mukherjee P, Fasano A, Le Ven J, Nicholson JK, Dumas ME, Khanna KM, Mani (2014) Symbiotic bacterial metabolites regulate gastrointestinal barrier function via the xenobiotic sensor PXR and toll-like receptor 4. Immunity 41, 296-310.

[110] Stadlbauer V, Engertsberger L, Komarova I, Feldbacher N, Leber B, Pichler G, Fink N, Scarpatetti M, Schippinger W, Schmidt R, Horvath A (2020) Dysbiosis, gut barrier dysfunction and inflammation in dementia: A pilot study. BMC Geriatr 20, 248.

[111] de la Cuesta-Zuluaga J, Kelley ST, Chen Y, Escobar JS, Mueller NT, Ley RE, McDonald D, Huang S, Swafford AD, Knight R, Thackray VG (2019) Age- and sexdependent patterns of gut microbial diversity in human adults. mSystems 4, e00261-19.

[112] Rizzetto L, Fava F, Tuohy KM, Selmi C (2018) Connecting the immune system, systemic chronic inflammation and the gut microbiome: The role of sex. J Autoimmun 92, 12-34.

[113] Org E, Mehrabian M, Parks BW, Shipkova P, Liu X, Drake TA, Lusis AJ (2016) Sex differences and hormonal effects 
on gut microbiota composition in mice. Gut Microbes 7 , 313-322.

[114] Morris A (2018) Microbiota drives sex-specific differences. Nat Rev Endocrinol 15, 4.

[115] Màrquez EJ, Chung $\mathrm{CH}$, Marches R, Rossi RJ, NeharBelaid D, Eroglu A, Mellert DJ, Kuchel GA, Banchereau J, Ucar D (2020) Sexual-dimorphism in human immune system aging. Nat Commun 11, 751.

[116] Phelps T, Snyder E, Rodriguez E, Child H, Harvey P (2019) The influence of biological sex and sex hormones on bile acid synthesis and cholesterol homeostasis. Biol Sex Differ 10, 52.

[117] Xiang X, Backman JT, Neuvonen PJ, Niemi M (2012) Gender, but not CYP7A1 or SLCO1B1 polymorphism, affects the fasting plasma concentrations of bile acids in human beings. Basic Clin Pharmacol Toxicol 110, 245-252.

[118] Frommherz L, Bub A, Hummel E, Rist MJ, Roth A, Watzl B, Kulling SE (2016) Age-related changes of plasma bile acid concentrations in healthy adults - results from the cross-sectional KarMeN study. PLoS One 11, e0153959.

[119] Ma J, Hong Y, Zheng N, Xie G, Lyu Y, Gu Y, Xi C, Chen L, Wu G, Li Y, Tao X, Zhong J, Huang Z, Wu W, Yuan L, Lin M, Lu X, Zhang W, Jia W, Sheng L, Li H (2020) Gut microbiota remodeling reverses aging-associated inflammation and dysregulation of systemic bile acid homeostasis in mice sex-specifically. Gut Microbes 11, 14501474.

[120] Sheng L, Jena PK, Liu HX, Kalanetra KM, Gonzalez FJ, French SW, Krishnan VV, Mills DA, Wan YJY (2017) Gender differences in bile acids and microbiota in relationship with gender dissimilarity in steatosis induced by diet and FXR inactivation. Sci Rep 7, 1748.

[121] Toni R (2004) The neuroendocrine system: Organization and homeostatic role. J Endocrinol Invest 27(6 Suppl), $35-47$.

[122] Mulak A (2020) An overview of the neuroendocrine system in Parkinson's disease: What is the impact on diagnosis and treatment? Expert Rev Neurother 20, 127-135.

[123] Drucker DJ, Nauck MA (2006) The incretin system: Glucagon-like peptide-1 receptor agonists and dipeptidyl peptidase- 4 inhibitors in type 2 diabetes. Lancet $\mathbf{3 6 8}$, 1696-1705.

[124] Brighton CA, Rievaj J, Kuhre RE, Glass LL, Schoonjans K, Holst JJ, Gribble FM, Reimann F (2015) Bile acids trigger GLP-1 release predominantly by accessing basolaterally located $\mathrm{G}$ protein-coupled bile acid receptors. Endocrinology 156, 3961-3970.

[125] Lim GE, Brubaker PL (2006) Glucagon-like peptide 1 secretion by the L-cell the view from within. Diabetes 55(Suppl 2), S70-S77.

[126] Holst JJ (2007) The physiology of glucagon-like peptide 1. Physiol Rev 87, 1409-1439.

[127] Nakagawa A, Satake H, Nakabayashi H, Nishizawa M, Furuya K, Nakano S, Kigoshi T, Nakayama K, Uchida K (2004) Receptor gene expression of glucagon-like peptide1 , but not glucose-dependent insulinotropic polypeptide, in rat nodose ganglion cells. Autonom Neurosci 110, 36-43.

[128] Grieco M, Giorgi A, Gentile MC, d'Erme M, Morano S, Maras B, Filardi T (2019) Glucagon-like peptide-1: A focus on neurodegenerative diseases. Front Neurosci 13, 1112 .

[129] Yildirim Simsir I, Soyaltin UE, Cetinkalp S (2018) Glucagon like peptide-1 (GLP-1) likes Alzheimer's disease. Diabetes Metab Syndr 12, 469-475.
[130] Reitz C, Mayeux R (2014) Alzheimer disease: Epidemiology, diagnostic criteria, risk factors and biomarkers. Biochem Pharmacol 88, 640-651.

[131] Brown E, Cuthbertson DJ, Wilding JP (2018) Newer GLP1 receptor agonists and obesity-diabetes. Peptides 100, 61-67.

[132] Batista AF, Bodart-Santos V, De Felice FG, Ferreira ST (2019) Neuroprotective actions of glucagon-like peptide-1 (GLP-1) analogues in Alzheimer's and Parkinson's diseases. CNS Drugs 33, 209-223.

[133] Sorrentino G, Perino A, Yildiz E, El Alam G, Bou Sleiman M, Gioiello A, Pellicciari R, Schoonjans K (2020) Bile acids signal via TGR5 to activate intestinal stem cells and epithelial regeneration. Gastroenterology 159, 956968.e8.

[134] Lund ML, Sorrentino G, Egerod KL, Kroone C, Mortensen B, Knop FK, Reimann F, Gribble FM, Drucker DJ, de Koning EJP, Schoonjans K, Bäckhed F, Schwartz TW, Petersen $\mathrm{N}$ (2020) L-cell differentiation is induced by bile acids through GPBAR1 and paracrine GLP-1 and serotonin signaling. Diabetes 69, 614-623.

[135] Kim DY, Camilleri M (2000) Serotonin: A mediator of the brain-gut connection. Am J Gastroenterol 95, 2698-2709.

[136] O'Mahony SM, Clarke G, Borre YE, Dinan TG, Cryan JF (2015) Serotonin, tryptophan metabolism and the braingut-microbiome axis. Behav Brain Res 277, 32-48.

[137] Schölmerich J, Becher MS, Schmidt K, Schubert R, Kremer B, Feldhaus S, Gerok W (1984) Influence of hydroxylation and conjugation of bile salts on their membranedamaging properties-studies on isolated hepatocytes and lipid membrane vesicles. Hepatology 4, 661-666.

[138] Rodrigues CM, Ma X, Linehan-Stieers C, Fan G, Kren BT, Steer CJ (1999) Ursodeoxycholic acid prevents cytochrome $\mathrm{c}$ release in apoptosis by inhibiting mitochondrial membrane depolarization and channel formation. Cell Death Differ 6, 842-854.

[139] Rodrigues CM, Stieers CL, Keene CD, Ma X, Kren BT, Low WC, Steer CJ (2000) Tauroursodeoxycholic acid partially prevents apoptosis induced by 3-nitropropionic acid: Evidence for a mitochondrial pathway independent of the permeability transition. J Neurochem 75, 2368-2379.

[140] Marksteiner J, Blasko I, Kemmler G, Koal T, Humpel C (2018) Bile acid quantification of 20 plasma metabolites identifies lithocholic acid as a putative biomarker in Alzheimer's disease. Metabolomics 14, 1.

[141] Hofmann AF, Hagey LR, Krasowski MD (2010) Bile salts of vertebrates: Structural variation and possible evolutionary significance. J Lipid Res 51, 226-246.

[142] Rudling M, Bonde Y (2015) Stimulation of apical sodiumdependent bile acid transporter expands the bile acid pool and generates bile acids with positive feedback properties. Dig Dis 33, 376-381.

[143] Xie C, Huang W, Young RL, Jones KL, Horowitz M, Rayner CK, Wu T (2021) Role of bile acids in the regulation of food intake, and their dysregulation in metabolic disease. Nutrients 13, 1104.

[144] Trefflich I, Marschall HU, Giuseppe RD, Ståhlman M, Michalsen A, Lampen A, Abraham K, Weikert C (2019) Associations between dietary patterns and bile acids-results from a cross-sectional study in vegans and omnivores. Nutrients 12, 47.

[145] Arora K, Green M, Prakash S (2020) The microbiome and Alzheimer's disease: Potential and limitations of prebiotic, synbiotic, and probiotic formulations. Front Bioeng Biotechnol 8, 537847. 
[146] Taniguchi Y, Shinkai S, Nishi M, Murayama H, Nofuji Y, Yoshida H, Fujiwara Y (2014) Nutritional biomarkers and subsequent cognitive decline among community-dwelling older Japanese: A prospective study. J Gerontol Ser A Biol Sci Med Sci 69, 1276-1283.

[147] Kai K, Hashimoto M, Amano K, Tanaka H, Fukuhara R, Ikeda M (2015) Relationship between eating disturbance and dementia severity in patients with Alzheimer's disease. PLoS One 10, e0133666.

[148] Koyama A, Hashimoto M, Tanaka H, Fujise N, Matsushita M, Miyagawa Y, Hatada Y, Fukuhara R, Hasegawa N, Todani S, Matsukuma K, Kawano M, Ikeda M (2016) Malnutrition in Alzheimer's disease, dementia with Lewy bodies, and frontotemporal lobar degeneration: Comparison using serum albumin, total protein, and hemoglobin level. PLoS One 11, e0157053.

[149] Kazemi S, Savabi G, Khazaei S, Savabi O, Esmaillzadeh A, Keshteli AH, Adibi P (2011) Association between food intake and oral health in elderly: SEPAHAN systematic review no. 8. Dent Res J (Isfahan) 8(Suppl 1), S15-20.

[150] Plaza-Díaz J, Ruiz-Ojeda FJ, Vilchez-Padial LM, Gil A (2017) Evidence of the anti-inflammatory effects of probiotics and synbiotics in intestinal chronic diseases. Nutrients 9, E555.

[151] Holmes A, Finger C, Morales-Scheihing D, Lee J, McCullough LD (2020) Gut dysbiosis and age-related neurological diseases; an innovative approach for therapeutic interventions. Transl Res 226, 39-56.

[152] Degirolamo C, Rainaldi S, Bovenga F, Murzilli S, Moschetta A (2014) Microbiota modification with probiotics induces hepatic bile acid synthesis via downregulation of the Fxr-Fgf15 axis in mice. Cell Rep 7, 12-18.

[153] Lye HS, Kato T, Low WY, Taylor TD, Prakash T, Lew LC, Ohno H, Liong MT (2017) Lactobacillus fermentum FTDC 8312 combats hypercholesterolemia via alteration of gut microbiota. J Biotechnol 262, 75-83.

[154] Akbari E, Asemi Z, Daneshvar Kakhaki R, Bahmani F, Kouchaki E, Tamtaji OR, Hamidi GA, Salami M (2016) Effect of probiotic supplementation on cognitive function and metabolic status in Alzheimer's disease: A randomized, double-blind and controlled trial. Front Aging Neurosci 8, 256.

[155] Jones ML, Martoni CJ, Parent M, Prakash S (2012) Cholesterol lowering efficacy of a microencapsulated bile salt hydrolase-active Lactobacillus reuteri NCIMB 30242 yoghurt formulation in hypercholesterolaemic adults. $\mathrm{Br}$ J Nutr 107, 1505-1513.

[156] Jena PK, Sheng L, Di Lucente J, Jin LW, Maezawa I, Wan YY (2018) Dysregulated bile acid synthesis and dysbiosis are implicated in Western diet-induced systemic inflammation, microglial activation, and reduced neuroplasticity. FASEB J 32, 2866-2877.

[157] Ghaffarzadegan T, Zhong y, Fåk Hållenius F, Nyman M (2018) Effects of barley variety, dietary fiber and $\beta$-glucan content on bile acid composition in cecum of rats fed lowand high-fat diets. J Nutr Biochem 53, 104-110.

[158] Perez-Pardo P, Kliest T, Dodiya HB, Broersen LM, Garssen J, Keshavarzian A, Kraneveld AD (2017) The gut-brain axis in Parkinson's disease: Possibilities for food-based therapies. Eur J Pharmacol 817, 86-95.

[159] Szablewski L (2018) Human gut microbiotain health and Alzheimer's disease. J Alzheimers Dis 62, 549-560.

[160] Morris MC, Tangney CC, Wang Y, Sacks FM, Bennett DA, Aggarwal NT (2015) MIND diet associated with reduced incidence of Alzheimer's disease. Alzheimers Dement 11, 1007-1014.

[161] Pistollato F, Iglesias RC, Ruiz R, Aparicio S, Crespo J, Lopez LD, Manna PP Giampieri F, Battino M (2018) Nutritional patterns associated with the maintenance of neurocognitive functions and the risk of dementia and Alzheimer's disease: A focus on human studies. Pharmacol Res 131, 32-43.

[162] Pushpass RAG, Alzoufairi S, Jackson KG, Lovegrove JA (2021) Circulating bile acids as a link between the gut microbiota and cardiovascular health: Impact of prebiotics, probiotics and polyphenol-rich foods. Nutr Res Rev, doi: 10.1017/S0954422421000081

[163] Vendrik KEW, Ooijevaar RE, de Jong PRC, Laman JD, van Oosten BW, van Hilten JJ, Ducarmon QR, Keller JJ, Kuijper EJ, Contarino MF (2020) Fecal microbiota transplantation in neurological disorders. Front Cell Infect Microbiol 10, 98.

[164] Hazan S (2020) Rapid improvement in Alzheimer's disease symptoms following fecal microbiota transplantation: A case report. J Int Med Res 48, 300060520925930.

[165] Weingarden AR, Chen C, Bobr A, Yao D, Lu Y, Nelson VM, Sadowsky MJ, Khoruts A (2014) Microbiota transplantation restores normal fecal bile acid composition in recurrent Clostridium difficile infection. Am J Physiol Gastrointest Liver Physiol 306, G310-319.

[166] Vang S, Longley K, Steer CJ, Low WC (2014) The unexpected uses of urso- and tauroursodeoxycholic acid in the treatment of non-liver diseases. Glob Adv Health Med 3, 58-69.

[167] Zangerolamo L, Vettorazzi JF, Rosa LRO, Carneiro EM, Barbosa HCL (2021) The bile acid TUDCA and neurodegenerative disorders: An overview. Life Sci 272, 119252.

[168] Ramalho RM, Borralho PM, Castro RE, Solà S, Steer CJ, Rodrigues CM (2006) Tauroursodeoxycholic acid modulates p53-mediated apoptosis in Alzheimer's disease mutant neuroblastoma cells. J Neurochem 98, 1610-1618.

[169] Keene CD, Rodrigues CM, Eich T, Chhabra MC, Steer CJ, Low WC (2002) Tauroursodeoxycholic acid, a bile acid, is neuroprotective in a transgenic animal model of Huntington's disease. Proc Natl Acad Sci U S A 99, 1067110676

[170] Duan WM, Rodrigues CM, Zhao LR, Steer CJ, Low WC (2002) Tauroursodeoxycholic acid improves the survival and function of nigral transplants in a rat model of Parkinson's disease. Cell Transplant 11, 195-205.

[171] Yanguas-Casàs N, Barreda-Manso MA, Nieto-Sampedro M, Romero-Ramírez, L (2014) Tauroursodeoxycholic acid reduces glial cell activation in an animal model of acute neuroinflammation. $J$ Neuroinflamm 11, 50.

[172] Nunes AF, Amaral JD, Lo AC, Fonseca MB, Viana RJ, Callaerts-Vegh Z, D'Hooge R, Rodrigues CM (2012) TUDCA, a bile acid, attenuates amyloid precursor protein processing and amyloid-beta deposition in APP/PS1 mice. Mol Neurobiol 45, 440-454.

[173] Solà S, Castro RE, Laires PA, Steer CJ, Rodrigues CM (2003) Tauroursodeoxycholic acid prevents amyloid-beta peptide-induced neuronal death via a phosphatidylinositol 3-kinase-dependent signaling pathway. Mol Med 9, 226-234.

[174] Ramalho RM, Ribeiro PS, Solà S, Castro RE, Steer CJ, Rodrigues CM (2004) Inhibition of the E2F-1/p53/Bax pathway by tauroursodeoxycholic acid in amyloid betapeptide-induced apoptosis of PC12 cells. J Neurochem $\mathbf{9 0}$, 567-575. 
[175] Viana RJ, Steer CJ, Rodrigues CM (2011) Amyloid- $\beta$ peptide-induced secretion of endoplasmic reticulum chaperone glycoprotein GRP94. J Alzheimers Dis 27, 61-73.

[176] Viana RJ, R Ramalho RM, Nunes AF, Steer CJ, Rodrigues CM (2010) Modulation of amyloid- $\beta$ peptide-induced toxicity through inhibition of JNK nuclear localization and caspase-2 activation. J Alzheimers Dis 22, 557-568.

[177] Fonseca MB, Nunes AF, Rodrigues CM (2012) c-Jun regulates the stability of anti-apoptotic $\triangle \mathrm{Np} 63$ in amyloid$\beta$-induced apoptosis. J Alzheimers Dis 28, 685-694.

[178] Viana RJ, Nunes AF, Castro RE, Ramalho RM, Meyerson J, Fossati S, Ghiso J, Rostangno A, Rodrigues CM (2009) Tauroursodeoxycholic acid prevents E22Q Alzheimer's Abeta toxicity in human cerebral endothelial cells. Cell Mol Life Sci 66, 1094-1104.

[179] Cash JG, Kuhel DG, Basford JE, Jaeschke A, Chatterjee TK, Weintraub NL, Hui DY (2012) Apolipoprotein E4 impairs macrophage efferocytosis and potentiates apoptosis by accelerating endoplasmic reticulum stress. $J$ Biol Chem 287, 27876-27884
[180] Ramalho RM, Nunes AF, Dias RB, Amaral JD, Lo AC, D'Hooge R, Sebastião AM, Rodrigues CM (2013) Tauroursodeoxycholic acid suppresses amyloid $\beta$-induced synaptic toxicity in vitro and in APP/PS1 mice. Neurobiol Aging 34, 551-561.

[181] Dionísio PA, Amaral JD, Ribeiro MF, Lo AC, D'Hooge R, Rodrigues CM (2015) Amyloid- $\beta$ pathology is attenuated by tauroursodeoxycholic acid treatment in APP/PS1 mice after disease onset. Neurobiol Aging 36, 228-240.

[182] Lo AC, Callaerts-Vegh Z, Nunes AF, Rodrigues CM, D'Hooge R (2013) Tauroursodeoxycholic acid (TUDCA) supplementation prevents cognitive impairment and amyloid deposition in APP/PS1 mice. Neurobiol Dis 50, 21-29.

[183] Fiorucci S, Distrutti E (2019) The pharmacology of bile acids and their receptors. Handb Exp Pharmacol 256, 3-18.

[184] Albillos A, de Gottardi A, Rescigno M (2020) The gutliver axis in liver disease: Pathophysiological basis for therapy. J Hepatol 72, 558-577. 